Article

\title{
Exploring DNA Methylation Diversity in the Honey Bee Brain by Ultra-Deep Amplicon Sequencing
}

\author{
Robert Kucharski ${ }^{1,2}$ and Ryszard Maleszka ${ }^{1, *}$ (D) \\ 1 Research School of Biology, Australian National University, Canberra, ACT 2601, Australia; \\ robert.kucharski@anu.edu.au \\ 2 Faculty of Science and Technology, University of Canberra, Canberra, ACT 2617, Australia \\ * Correspondence: ryszard.maleszka@anu.edu.au
}

Received: 11 November 2019; Accepted: 22 June 2020; Published: 25 June 2020

\begin{abstract}
Understanding methylation dynamics in organs or tissues containing many different cell types is a challenging task that cannot be efficiently addressed by the low-depth bisulphite sequencing of DNA extracted from such sources. Here we explored the feasibility of ultra-deep bisulphite sequencing of long amplicons to reveal the brain methylation patterns in three selected honey bee genes analysed across five distinct conditions on the Illumina MiSeq platform. By combing 15 libraries in one run we achieved a very high sequencing depth of 240,000-340,000 reads per amplicon, suggesting that most of the cell types in the honey bee brain, containing approximately 1 million neurons, are represented in this dataset. We found a small number of gene-specific patterns for each condition in individuals of different ages and performing distinct tasks with $80-90 \%$ of those were represented by no more than a dozen patterns. One possibility is that such a small number of frequent patterns is the result of differentially methylated epialleles, whereas the rare and less frequent patterns reflect activity-dependent modifications. The condition-specific methylation differences within each gene appear to be position-dependent with some CpGs showing significant changes and others remaining stable in a methylated or non-methylated state. Interestingly, no significant loss of methylation was detected in very old individuals. Our findings imply that these diverse patterns represent a special challenge in the analyses of DNA methylation in complex tissues and organs that cannot be investigated by low-depth genome-wide bisulphite sequencing. We conclude that ultra-deep sequencing of gene-specific amplicons combined with genotyping of differentially methylated epialleles is an effective way to facilitate more advanced neuro-epigenomic studies in honey bees and other insects.
\end{abstract}

Keywords: DNA methylation; epialleles; brain epigenome; cellular diversity; social insect; gene expression; nadrin; dynactin

\section{Introduction}

Tissues with a high level of cellular complexity, such as the brain, represent a special challenge in epigenomic analyses [1,2]. Although many brain cell types can be easily defined on the basis of their morphology, connectivity and specific locations or transmitter repertoires, we are still largely ignorant of how many functionally distinct cells may exist even in a relatively simple invertebrate brain [3]. In Drosophila, an old assessment that the intrinsic neurons (Kenyon cells) of the brain centres, known as mushroom bodies, are functionally identical isomorphic arrays, was radically reshaped following the development of the enhancer trap-based methodology [4]. It has been shown that these cells form parallel sub-compartments, exhibiting discrete patterns of gene expression [4]. Similarly, distinct patterns of spatial expression of cell type-specific genes have been found in the main compartments and small regional subdivisions of the mouse brain [5]. At the epigenomic level, the potential of 
differentially methylated genomic regions to define functionally distinct cell types was investigated in the human brain [6]. These findings suggest that subsets of morphologically similar brain cells could have diverse "molecular identities", established either during development or as a result of activity-dependent changes, or both, and may specify the functionally distinct cell types of the neurons and glia.

Although much progress has been made in unravelling the basic aspects of epigenomic modifications in mammals, the sheer complexity of mammalian brains combined with their heavily methylated genomes represents a major experimental impediment in these studies, in particular at the level of functional cell-type resolution [7-10]. This is an area in which excellent progress can be made using smaller brains of sophisticated insects, such as the social honey bee, Apis mellifera [3,11,12].

The discovery of a DNA methylation system in the honey bee [12,13] has created an excellent opportunity to study DNA methylation dynamics in a sophisticated organism with a compact, sparsely methylated genome and a relatively small, yet sufficiently complex brain that controls an advanced behavioural repertoire, including navigational skills, long term memory and the only known non-primate symbolic "language" [14]. The seminal mapping of the whole adult brain and larval head methylomes in honey bee queens and workers provides the initial impetus for the emerging field of comparative neuro-epigenomics $[15,16]$. However, it became clear that in this polyandrous organism a high proportion of differential methylation is driven by obligatory epialleles, whose impact on genome regulation is poorly understood $[8,17,18]$.

We hypothesized that functionally distinct cell types in the insect brain could be identified on the basis of the methylation patterns of illustrator genes generated by sequencing of long amplicons at high depth. In contrast to the low-depth (5-20x coverage) genome-wide methylation profiles that are assembled from short 75-100 base pairs (bp) reads, representing the combined methylomes of many different cell types, Illumina platforms such as MiSeq or NovaSeq allow for analysing sequence lengths of $\sim 600 \mathrm{bp}$ and at a depth of many thousand reads per amplicon [19]. Assuming predominantly symmetrical CpG methylation in the honey bee [20], and each read representing a single-strand DNA methylation event in one chromosome per nucleus, the resolving power of this approach has the potential to visualize all condition-specific patterns that may be associated with epigenetically distinct cell types. Furthermore, many conditions can be sequenced in parallel in one run.

Here, we have asked how many diverse methylation patterns can be detected in the honey bee brain during various stages of adult maturation and in individuals preforming different tasks. Three conserved genes expressed in the brain with a relatively high number of confirmed methylated CpGs were selected as illustrators of methylation changes (Table 1). The five chosen conditions represent important situations of great interest for studies on the behaviour and adult maturation in honey bees that are either shown or predicted to be epigenetically controlled $[8,15,16,21]$ (Table 2): (1) 7-day-old bees reared in a dark incubator with very little life experience and no colony-level experience; (2) 14-day-old bees getting ready for a major life transition, namely nurse-to-forager. These bees undertook orientation flights and their brains have the initial activity-dependent imprints driven by light and spatial learning; (3) and (4) two groups of 93-day-old bees, representing two distinct functional categories, namely nurses and foragers. This is a most interesting group that allows for exploring differences driven by task rather than age; and (5) very old bees that were selected to examine the potential effect of age on methylation. We show that distinct patterns of methylated CpGs in the honey bee brain are easily detectable in various situations by employing ultra-deep amplicon sequencing. We argue that the significance of DNA methylation with respect to behaviour and adult maturation can be effectively studied by this approach.

\section{Results}

Both the quality and quantity of reads generated by Illumina MiSeq in our experiments have consistently been excellent, yielding 240,000-340,000 reads per amplicon. Although like in other species, the number of cell types in the honey bee brain is not known, and such coverage and the 
length of amplicons ensures that most if not all methylation patterns potentially associated with a given gene/condition can be visualised in a population of around 1 million neurons [22].

The three genes selected for this project, dynactin, nadrin and pkcbp1 (Table 1 and Figures S1-S3), have previously been shown to be methylated by the whole genome bisulphite sequencing $[15,19]$. All three genes have a relatively high number of methylated CpGs (Table 1 and Figure 1, Figures S4 and S5) and produce alternatively spliced transcripts. Some correlative evidence from the honey bee transcriptome and methylomes suggest that methylated CpGs may play a role in alternative splicing. In the case of pkcbp1, two methylated CpGs have been implicated in generating two splice variants encoding distinct protein isoforms (Figure S3). All three genes encode proteins with known roles in various organisms and given their high level of conservation are predicted to have similar roles in the honey bee brain, namely cytoskeletal rearrangements, cell differentiation and cellular signalling $[19,21]$.

Table 1. Description of the amplicons. The table shows the NCBI accession numbers, exons covered by nested PCR products and nested product lengths created using the primer sets described previously [23].

\begin{tabular}{|c|c|c|c|c|c|}
\hline Gene & NCBI IDs & $\begin{array}{l}\text { Analysed } \\
\text { Exons }\end{array}$ & $\begin{array}{c}\text { Amplicon } \\
\text { Length (bp) } * *\end{array}$ & $\begin{array}{c}\text { mCpGs/ } \\
\text { Amplicon }\end{array}$ & Comments \\
\hline $\begin{array}{c}\text { Dynactin * } \\
\text { dctn4 subunit } 4\end{array}$ & XP_006560650 & $4,5,6$ & 551 & 10 & $\begin{array}{l}\text { Differentially spliced, } \\
\text { methylated in queen and } \\
\text { worker adult brain and } \\
\text { in larval head }\end{array}$ \\
\hline $\begin{array}{c}\text { PKCbp1, } \\
\text { protein kinase } \\
\text { C-binding protein }\end{array}$ & XP_016769618 & 5,6 & 401 & 10 & $\begin{array}{c}\text { Methylated gene, } \\
\text { different isoforms } \\
\text { expressed in adult brains } \\
\text { and larval heads }\end{array}$ \\
\hline
\end{tabular}

* The BeeBase annotation of Dynactin shows a gene model with 10 exons, whereas the NCBI shows a gene model with 9 exons. The extra exon in BeeBase is located between NCBI exons 7 and 8 . Our RNA seq data support the NCBI model (see Figure S2 for dctn4 gene model and References [16] and [24] for accession numbers). ** Not including adaptors and indices.

Figure 1 shows the patterns of nadrin methylation in the honey bee brain across all five analysed conditions, including bees of different ages and experience. Interestingly, we have found a tendency of certain CpG sites to show high methylation dynamics (e.g., CpG \#11) with other sites remaining almost unchanged as unmethylated (e.g., CpG \#3) or methylated (e.g., CpG \#12). In the case of nadrin, the middle part of the analysed gene fragment shows higher methylation dynamics than the flanking regions, which appear to change only moderately (Figure 1). The methylation of the other two analysed genes, dynactin and $p k c b p 1$, follows a similar arrangement with the majority of the detected CpGs showing little dynamics. While the bulk of the condition-specific patterns is represented by only a few configurations of methylated CpGs, there are additional less-frequent patterns detectable in each situation. At this stage it is difficult to determine if these rare patterns are genuine or if they represent technical noise, resulting, for example, from the nature of the sequencing technology. Alternatively, these less frequent patterns could represent changes in methylation driven by behavioural activities or external stimuli. Such activity-dependent modification take place only in restricted areas of the brain and therefore are intermittent $[8,14]$. Applying different pattern frequency cut-offs reduces the number of both unique patterns and overlapping patterns between different situations. However, the overall conclusions remain unchanged regardless of the applied cut-offs. One example of a 2-way comparison of nadrin methylation patterns in 7-day- and 14-day-old bees is shown in Figure 2. Perhaps not surprisingly, the most similar patterns were found in individuals of the same age (93 days) but performing distinct tasks (nurses vs. foragers). The Venn diagrams in Figure 3 show a compilation of all the patterns in the three analysed genes across all five conditions. The number of overlapping patterns is minimal, even with the $1 \%$ frequency cut-off. Our data also confirm that there are more 
methylation changes associated with age than with tasks. The number of age-related patterns for young and old doubles the number of patterns found in nurses and foragers of the same age (Figure 4). With regard to age, we find only a moderate loss of the overall methylation in 93-day-old bees versus 7and 14-day-old bees, with no further decrease in the oldest individuals (118-day-old bees).

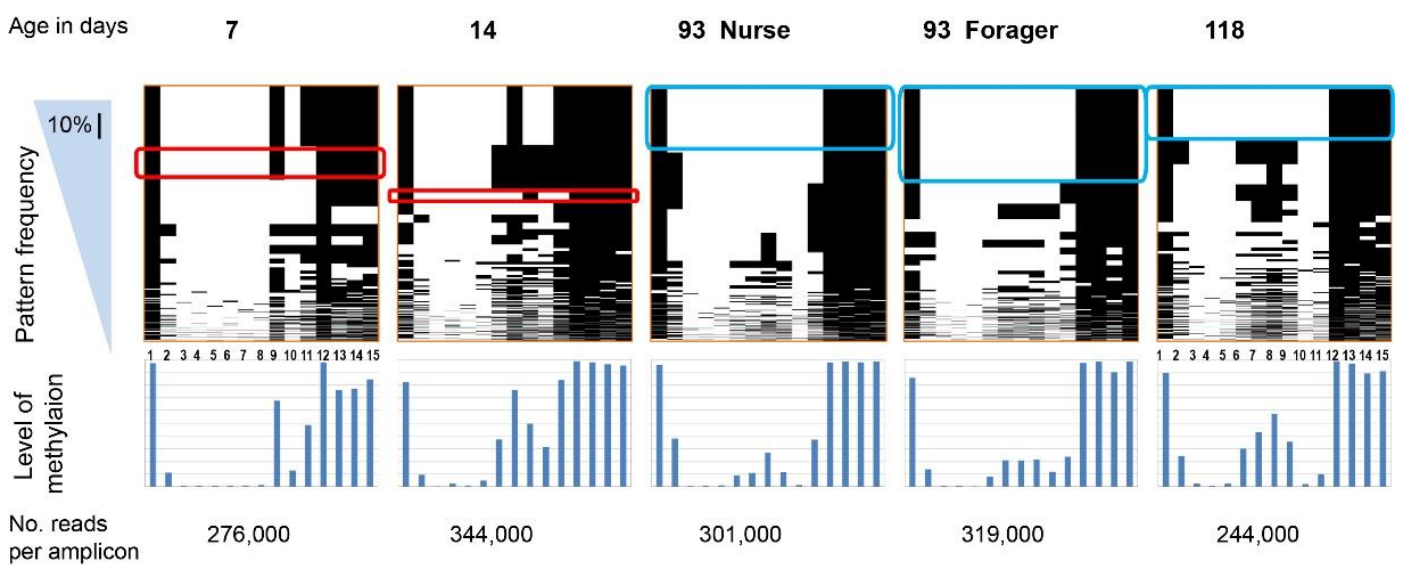

Figure 1. All methylation patterns for $15 \mathrm{CpG}$ sites in the nadrin amplicon revealed by Illumina MiSeq; "Frequency" denotes the pattern sorting direction (i.e., most frequent patterns at the top). The scale bar in the blue triangle corresponds to $10 \%$ of all patterns. The lower panel shows the combined methylation level for each CpG. The rounded red and blue rectangles indicate selected identical patterns between two or three situations. The age of the bees used is shown above the top panel (see Table 2 for a full description of the biological material). For details on the nadrin gene structure and amplicon localisation, see Figure S1 and Table 1. The number of reads per amplicon is indicated at the bottom.

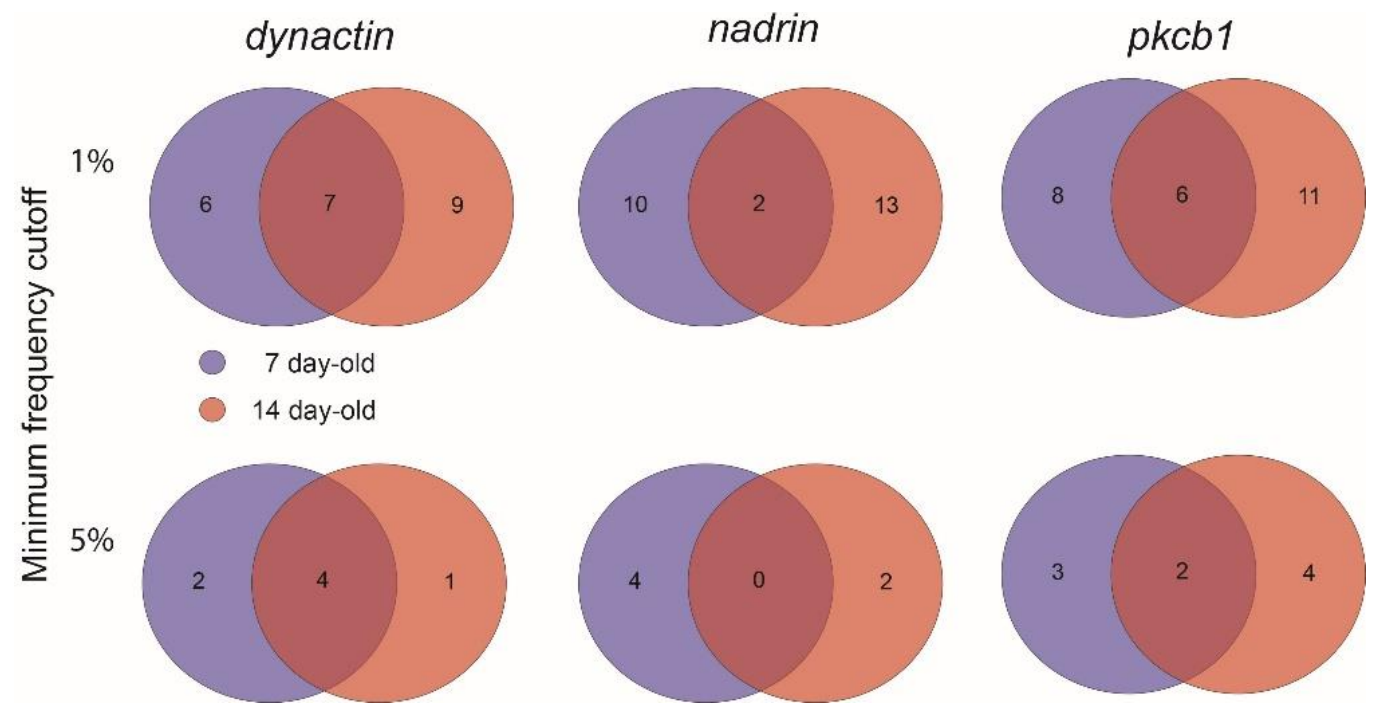

Figure 2. A 2-way Venn diagram showing the number of unique and overlapping patterns for dynactin, nadrin and pkcb1 in 7-day-old and 14-day-old bees (1\% and 5\% minimum frequency cut-off). 

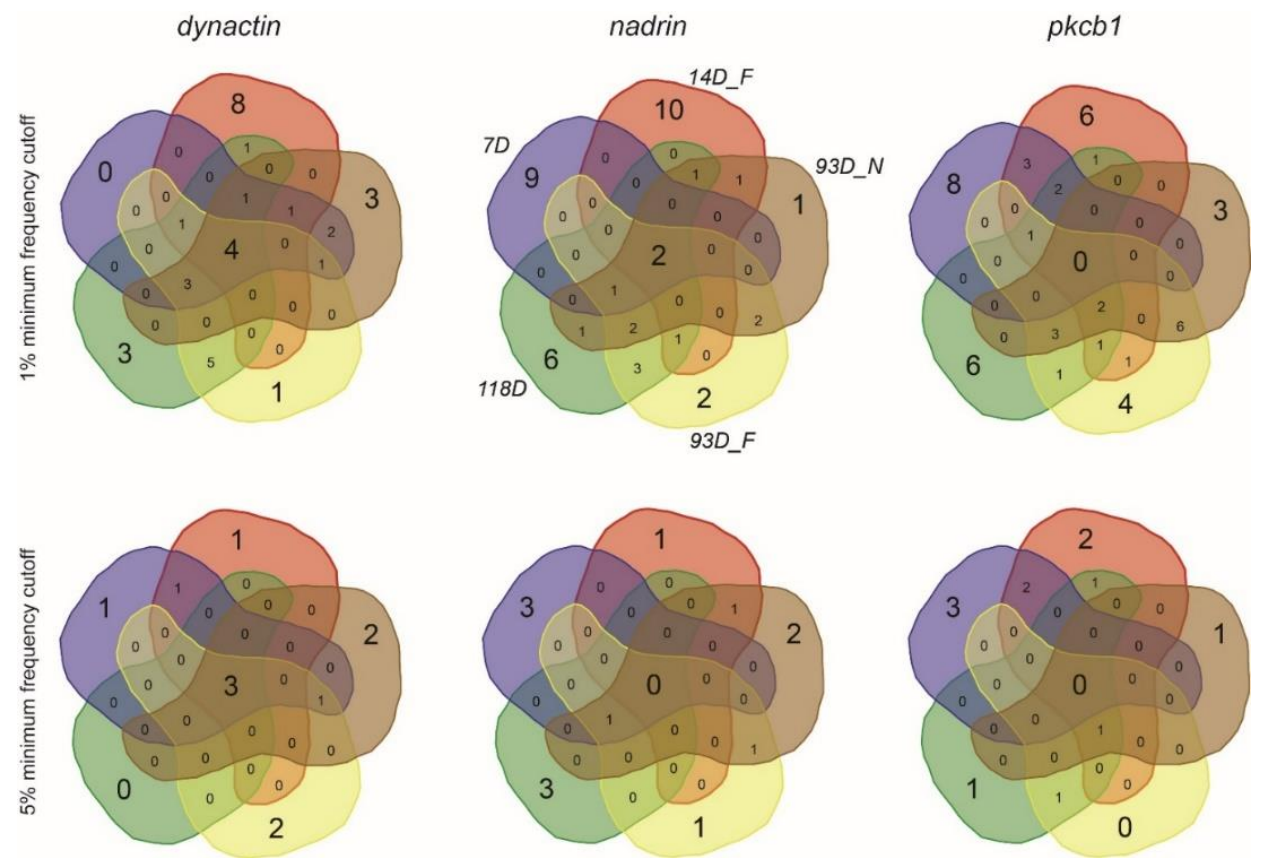

Figure 3. Symmetrical Venn diagrams showing the number of unique and overlapping patterns for dynactin, nadrin and $p k c b 1$ from all the analysed conditions ( $1 \%$ and $5 \%$ minimum frequency cut-off).

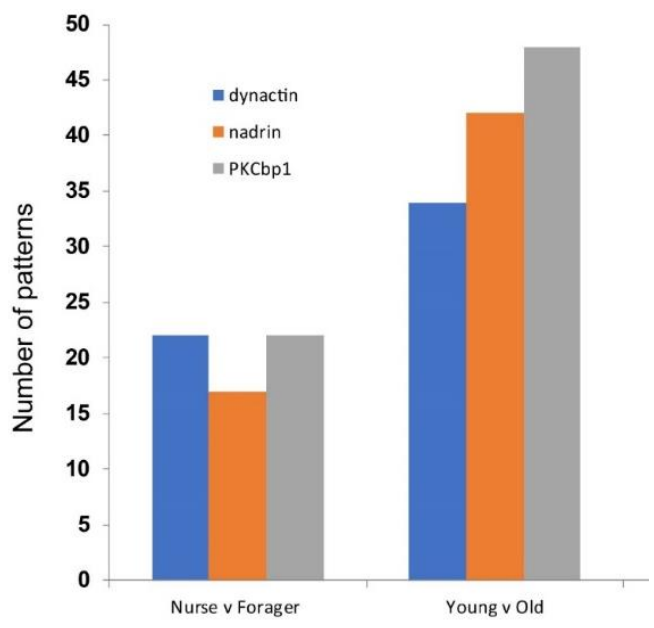

Figure 4. Number of cumulative patterns for dynactin, nadrin and $p k c b 1$ with a minimum $1 \%$ frequency, 2-way comparisons: nurses versus foragers (all 93-day-old bees) and young bees (combined 7- and 14-day-old bees) versus old bees (combined 93-day-old nurses and foragers and 118-day-old bees).

\section{Discussion}

\subsection{What Is the Meaning of the Novel Methylation Patterns Uncovered by this Study?}

There are several important conclusions emerging from this study. First, the number of condition-specific methylation patterns is low, suggesting that they may correlate with the epigenetic polymorphism (epialleles) in individuals analysed in each group. Indeed, the combined contribution of maternal/paternal patterns in the pooled sample of five bees used for each situation is expected to roughly yield the observed frequency of the main patterns. The relevance of the genetic polymorphism to methylomics in this polyandrous organism was highlighted in a couple of recent studies $[18,25]$. These studies suggest that the obligatory epialleles arising from sequence variations are most likely the main source of differential methylation between various situations previously found in the honey bee $[15,16]$. In this context, the mapping of any potential de novo methylation marks driven by 
brain activities poses a greater challenge. It is conceivable that in our dataset such a limited de novo methylation is represented by the infrequent patterns. This notion is supported by our recent finding that the full extent of $\mathrm{CpG}$ methylation in a gene encoding AmDAT (dopamine transporter) could only be revealed by ultra-deep sequencing [26]. Given the restricted expression of AmDAT in just four clusters of neurons in the honey bee brain [27], this result is not surprising, and in addition, it reinforces the idea that at least in some cases DNA methylation is positively correlated with transcription [25]. Since the overall number of patterns in the honey bee brain is manageable, the contribution of epialleles and de novo methylation to the honey bee brain methylomes can be experimentally resolved by deep amplicon sequencing combined with genotyping. Secondly, there is very little overlap between the patterns seen in the different conditions with both age and function correlating with the different patterns. Thirdly, certain CpG dinucleotides are more prone to methylation changes than others. The extent to which the observed methylation patterns are relevant to brain function cannot be clearly established without a full understanding of the effects of individual CpGs on gene expression. One possibility is that such variable differentially methylated regions represent hotspots for interactions with chromatin [28] or microRNAs [24] and may be important for transcript quality and/or quantity control $[17,25,29-31]$. Like in many other honey bee genes, some of the methylated CpGs analysed in this study are localised in the region where alternatively spliced variants are generated (Figure S3). Alternatively, changes in the methylation status of the CpGs in a given region may affect the level of transcription in accord with the idea that methylation alone or in combination with chromatin modifications can modulate gene expression $[17,28]$. In the mouse, non-promoter DNA methylation may be used for maintaining the active chromatin states of genes critical for development [32], and in Arabidopsis, DNA methylation can act to fine-tune gene expression by balancing the repressive and activating transcriptional effects [33]. An alternative explanation is that in a germ line this could be a way of "registering" activity and transferring this mark to the next generation $[8,18]$. By employing the strategy outlined in the present study, it should be possible to understand the extent of the fluidity and possibly the stochasticity as well as hereditability of the DNA methylation patterns in the honey bee, and the role they may play in behaviour and development.

\subsection{Experimental Inferences}

The massively parallel amplicon sequencing allows for analysing methylation patterns in genes of interest across several conditions, even if the methylation levels in certain cell types may be very low. Another advantage over low-coverage genome-wide bisulphite sequencing is that a given pattern is not generated from a small number of shorts reads, and thus different cells indicate only the cumulative levels of methylation at a given $\mathrm{CpG}$ rather than the individual cell-type patterns. In contrast, specific methylation of many CpGs in a $\sim 600$ bp region can be revealed with a depth of several thousand reads per one amplicon for thousands of cells. Similar sequencing depths of long DNA fragments can also be achieved on newer NGS platforms, such as NovaSeq, but such options are still more expensive than MiSeq.

Although the general levels of methylation in individual CpGs are similar to those found in previous genome-wide mapping in this species $[15,16]$, the actual patterns are novel because such patterns cannot be inferred from short sequencing reads obtained at a much lower depth and then mapped onto a genome assembly. Previously available methylation maps for a given genomic region represented combined patterns of many cells. In some studies, the sequencing depth was only 5-10× per read, with occasional efforts reaching 10-20x coverage [19]. While such methylomes are useful in uncovering the methylated regions, they offer little information about condition-specific methylation dynamics across diverse cell types. In the present study, the coverage of at least 240,000 reads per amplicon reveals a number of previously undetectable patterns that might delineate potential hotspots of methylation dynamics. Although most of these differentially methylated patters are likely to be generated by epiallelic differences, the less frequent patterns may represent de novo methylation/demethylation. Regardless of the means by which these diverse methylation patterns are 
produced, their impact on gene expression is predicted to be important in various contexts. Previous findings in plants and mammals suggest that DNA methylation variation is influenced by genetic and epigenetic changes that are often stably inherited and can influence the expression of nearby genes [29,31].

We show that a massively parallel sequencing of relatively long amplicons with Illumina MiSeq technology can be used to reveal the methylation patterns of specific genes at a previously inconceivable depth, which is more than enough to visualise the methylation patterns of the entire bee brain. This approach offers a great potential to analyse the condition-specific brain methylation dynamics in the honey bee. These results are promising and suggest that technical issues are no longer a limiting factor in generating the methylation profiles of virtually all cell types in whole insect brains, or even selected regions of vertebrate brains. An important implication of our findings is that the epigenomic signatures in multicellular organs must be studied at the level of a specific cell group rather than using whole-brain extracts. A sufficient sequencing depth of long reads needs to be achieved to reveal all potential patterns.

\section{Materials and Methods}

\subsection{Honey Bees and Brain Dissections}

Honey bees were collected from our colonies located at the ANU Campus Field Station (Canberra, Australia). Newly emerged bees were labelled with paint and either transferred to small cages (15 per cage) or returned to the hive. We have used brains from young behaviourally naive bees and contrasted them with brains of mid-age bees and old bees involved in specific tasks, namely nursing (brood feeding) and pollen collection. The 7-day-old naive bees collected from the cages were not involved in any tasks and their brains were not exposed to external stimuli. The 93-day-old foragers carrying pollen were collected at hive entrance; 93-day-old "nurses" were collected from brood frames while feeding larvae (they had large hypo-pharyngeal glands and no visible wing damage in contrast to foragers that had withered glands and damaged wings). More details are provided in Table 2. Brains were dissected from freshly collected individuals chilled on ice. Special care was taken to prevent gland contamination, typically by removing the membrane surrounding the brain tissue. This step should not last longer than two minutes. Following the dissection, each brain was immediately frozen on dry ice until the extraction step. Five brains were pooled for each group before DNA extraction.

Table 2. Description of the honey bees used in this study.

\begin{tabular}{ccc}
\hline Age of Bees (Days) & Functional Status & Comments \\
\hline 7 & $\begin{array}{c}\text { Caged bees reared in a dark } \\
\text { incubator } \\
\text { Hive bees that undertook } \\
\text { orientation flights } \\
\text { Mature hive nurse bees } \\
\text { Mature foragers }\end{array}$ & $\begin{array}{c}\text { No social colony-level environment, no specialised behavioural } \\
\text { experience. Medium HPGs* }\end{array}$ \\
93 & $\begin{array}{c}\text { These individuals were preparing for foraging. Medium HPGs } \\
\text { Collected carrying pollen. Vestigial HPGs, evidence of wing damage } \\
\text { Very old nurse bees }\end{array}$ & $\begin{array}{c}\text { Large HFG, possibly some prior foraging experience, but external body } \\
\text { damage, e.g., hair loss might be related to age }\end{array}$ \\
\hline
\end{tabular}

${ }^{*}$ HPG—hypopharyngeal gland. This gland is an indicator of a nurse or forager status [34]. A pool of five brains was analysed for each group.

\subsection{DNA Bisulphite Conversion and Amplicon Preparation}

A total of $1.5 \mu \mathrm{g}$ of brain DNA [23] was bisulphite-converted using the QIAGEN Epitect ${ }^{\circledR}$ Bisulfite Kit, as per the manufacturer's protocol (Hilden, Germany). With this kit we typically perform two consecutive treatments to avoid incomplete conversion, especially in GC-rich regions [35]. The converted DNA was amplified via a nested PCR reaction (40 cycles) with gene specific primers (the bisulfite-sequencing primers have been described elsewhere [21]). The PCR products were purified utilising an Agencourt ${ }^{\circledR}$ AMPure ${ }^{\circledR}$ XP PCR Purification system (Beckman Coulter, Brea, CA, USA). 


\subsection{NGS Library Preparation and MiSeq Sequencing}

Libraries were prepared from 500-600 ng of each amplicon utilising the NEBNext ${ }^{\circledR}$ DNA Library Prep Master Mix for Illumina ${ }^{\circledR}$, and NEBNext ${ }^{\circledR}$ Multiplex Oligos for Illumina ${ }^{\circledR}$ Index Primers Set 1 and Set2 (New England Biolabs, Ipswich, MA, USA). Size selection of the adaptor ligated DNA was performed using Agencourt AMPure XP beads (Beckman Coulter), with the bead:DNA ratio of the first bead selection $0.9 \times$, followed by a second bead selection with a bead:DNA ratio at $0.2 \times$. Each library was eluted in $30 \mu \mathrm{L}$ of $0.1 \times \mathrm{TE}$, and the library size confirmed via agarose gel electrophoresis (we used Caliper LabChip GXII and the HT DNA High Sensitivity Assay (Midland, ON, Canada was performed on an Illumina MiSeq instrument using MiSeq Reagent Kit v3 (Illumina) and 600 cycles. A PhiX spike was added at $5 \%$ concentration as recommended by Illumina for low-diversity libraries.

\subsection{Analysis of Bisulfite Sequencing Results}

For each analysed sample, the frequency at which an $\mathrm{mCpG}$ occurred was calculated across all reads using custom Python scripts and open-source software. The process was comprised of two steps. In the first step, pairs of reads with the 30 nucleotide sequence starting at position 4 matching exactly the last 30 nucleotides of the primers used for the nested amplicon PCR were extracted from FASTQ files, aligned with an in silico bisulphite-converted genomic template using MUSCLE [35]; overlapping regions (if any) were proportionally truncated and, after removing all aligner-introduced gaps, both reads were combined into one continuous sequence and appended to a separate file ("extract file") for each amplicon and each library/sample. In addition, a quality filter was applied, rejecting all sequences shorter than $90 \%$ of the length of the template or containing in excess of $5 \%$ gaps. In the second step, batches of sequences from the "extract" files were re-aligned with the template using MUSCLE (to eliminate any potential positional errors introduced by read indels), the aligned template sequence was used to calculate positional information of all the expected CpGs and SNPs and the positional data were used to score the methylation status (i.e., 0 for $\mathrm{T}$ and 1 for $\mathrm{C}$ occurring at a $\mathrm{CpG}$ position) for each combined read pair. The data were next appended to a separate table, and the unique methylation patterns were identified, and each unique pattern's cumulative count was calculated for each amplicon and each library/sample. The pattern counts tables were next processed with the R package MPFE [36] to estimate the distribution of the methylation patterns, to eliminate spurious patterns and to generate the patterns plots. Several modifications to various steps of this protocol have been described in other papers $[20,25,37]$.

Supplementary Materials: The following are available online at http://www.mdpi.com/2075-4655/4/2/10/s1.

Author Contributions: Conceptualization, R.M. and R.K.; Methodology, R.K.; Formal Analysis, R.K.; Resources, R.M.; Writing-Original Draft Preparation, R.M.; Writing-Review \& Editing, R.M. and R.K.; Project Administration, R.M. All authors have read and agreed to the published version of the manuscript.

Funding: This research received no external funding.

Conflicts of Interest: The authors declare no conflict of interest.

\section{References}

1. Albright, T.D.; Jessell, T.M.; Kandel, E.R.; Posner, M.I. Neural science: A century of progress and the mysteries that remain. Cell 2000, 100, S1-S55. [CrossRef]

2. Bargmann, C.I.; Marder, E. From the connectome to brain function. Nat. Methods 2013, 10, 483-490. [CrossRef] [PubMed]

3. Miklos, G.L.G.; Maleszka, R. Epigenomic communication systems in humans and honey bees: From molecules to behavior. Horm. Behav. 2011, 59, 399-406. [CrossRef]

4. Yang, M.Y.; Armstrong, J.D.; Vilinsky, I.; Strausfeld, N.J.; Kaiser, K. Subdivision of the Drosophila mushroom bodies by enhancer-trap expression patterns. Neuron 1995, 15, 45-54. [CrossRef] 
5. Ko, Y.; Ament, S.A.; Eddy, J.A.; Caballero, J.; Earls, J.C.; Hood, L.; Price, N.D. Cell type-specific genes show striking and distinct patterns of spatial expression in the mouse brain. Proc. Natl. Acad. Sci. USA 2013, 110, 3095-3100. [CrossRef]

6. Montano, C.M.; Irizarry, R.A.; Kaufmann, W.E.; Talbot, K.; Gur, R.E.; Feinberg, A.P.; Taub, M.A. Measuring cell-type specific differential methylation in human brain tissue. Genome Biol. 2013, 14, R94. [CrossRef]

7. Turner, B.M. Defining an epigenetic code. Nat. Cell Biol. 2007, 9, 2-6. [CrossRef]

8. Maleszka, R. Epigenetic code and insect behavioural plasticity. Curr. Opin. Insect Sci. 2016, 15, 45-52. [CrossRef]

9. Lister, R.; Pelizzola, M.; Dowen, R.H.; Hawkins, R.D.; Hon, G.; Tonti-Filippini, J.; Nery, J.R.; Lee, L.; Ye, Z.; Ngo, Q.M.; et al. Human DNA methylomes at base resolution show widespread epigenomic differences. Nature 2009, 462, 315-322. [CrossRef]

10. Lister, R.; Mukamel, E.A.; Nery, J.R.; Urich, M.; Puddifoot, C.A.; Johnson, N.D.; Lucero, J.; Huang, Y.; Dwork, A.J.; Schultz, M.D.; et al. Global epigenomic reconfiguration during mammalian brain development. Science (N. Y.) 2013, 341, 629-640. [CrossRef]

11. Maleszka, R. Epigenetic integration of environmental and genomic signals in honey bees: The critical interplay of nutritional, brain and reproductive networks. Epigenetics 2008, 3, 188-192. [CrossRef] [PubMed]

12. Lyko, F.; Maleszka, R. Insects as innovative models for functional studies of DNA methylation. Trends Genet. 2011, 27, 127-131. [CrossRef] [PubMed]

13. Wang, Y.; Jorda, M.; Jones, P.L.; Maleszka, R.; Ling, X.; Robertson, H.M.; Mizzen, C.A.; Peinado, M.A.; Robinson, G.E. Functional CpG methylation system in a social insect. Science (N. Y.) 2006, 314, 645-647. [CrossRef]

14. Menzel, R. The honeybee as a model for understanding the basis of cognition. Nat. Rev. Neurosci. 2012, 13, 758-768. [CrossRef]

15. Lyko, F.; Foret, S.; Kucharski, R.; Wolf, S.; Falckenhayn, C.; Maleszka, R. The honey bee epigenomes: Differential methylation of brain DNA in queens and workers. PLoS Biol. 2010, 8, e1000506. [CrossRef]

16. Foret, S.; Kucharski, R.; Pellegrini, M.; Feng, S.H.; Jacobsen, S.E.; Robinson, G.E.; Maleszka, R. DNA methylation dynamics, metabolic fluxes, gene splicing, and alternative phenotypes in honey bees. Proc. Natl. Acad. Sci. USA 2012, 109, 4968-4973. [CrossRef] [PubMed]

17. Wedd, L.; Maleszka, R. DNA methylation and gene regulation in honeybees: From genome-wide analyses to obligatory epialleles. Adv. Exp. Med. Biol. 2016, 945, 193-211. [CrossRef] [PubMed]

18. Yagound, B.; Smith, N.M.A.; Buchmann, G.; Oldroyd, B.P.; Remnant, E.J. Unique DNA methylation profiles are associated with cis-variation in honey bees. Genome Biol. Evol. 2019, 11, 2517-2530. [CrossRef]

19. Kucharski, R.; Foret, S.; Maleszka, R. EGFR gene methylation is not involved in royalactin controlled phenotypic polymorphism in honey bees. Sci. Rep. 2015, 5, 14070. [CrossRef]

20. Welsh, L.; Maleszka, R.; Foret, S. Detecting rare asymmetrically methylated cytosines and decoding methylation patterns in the honeybee genome. R. Soc. Open Sci. 2017, 4, 170248. [CrossRef]

21. Lockett, G.A.; Kucharski, R.; Maleszka, R. DNA methylation changes elicited by social stimuli in the brains of worker honey bees. Genes Brain Behav. 2012, 11, 235-242. [CrossRef]

22. Witthoft, W. Anzahl und Verteilung der Zellen im Hirn der Honigbiene. Z. Morphol. Tiere 1967, 61, 160-184. [CrossRef]

23. Wojciechowski, M.; Rafalski, D.; Kucharski, R.; Misztal, K.; Maleszka, J.; Bochtler, M.; Maleszka, R. Insights into DNA hydroxymethylation in the honeybee from in-depth analyses of TET dioxygenase. Open Biol. 2014, 4, 140110. [CrossRef] [PubMed]

24. Ashby, R.; Foret, S.; Searle, I.; Maleszka, R. MicroRNAs in honey bee caste determination. Sci. Rep. 2016, 6, 18794. [CrossRef] [PubMed]

25. Wedd, L.; Kucharski, R.; Maleszka, R. Differentially methylated obligatory epialleles modulate context-dependent LAM gene expression in the honeybee Apisb mellifera. Epigenetics 2016, 11, 1-10. [CrossRef] [PubMed]

26. Zhang, V.; Kucharski, R.; Landers, C.; Richards, S.N.; Bröer, S.; Martin, R.E.; Maleszka, R. Characterization of a dopamine transporter and its splice variant reveals novel features of dopaminergic regulation in the honey bee. Front. Physiol. 2019, 10, 1375. [CrossRef] 
27. Tedjakumala, S.R.; Rouquette, J.; Boizeau, M.L.; Mesce, K.A.; Hotier, L.; Massou, I.; Giurfa, M. A tyrosine-hydroxylase characterization of dopaminergic neurons in the honey bee brain. Front. Syst. Neurosci. 2017, 11, 47. [CrossRef]

28. Wojciechowski, M.; Lowe, R.; Maleszka, J.; Conn, D.; Maleszka, R.; Hurd, P.J. Phenotypically distinct female castes in honey bees are defined by alternative chromatin states during larval development. Genome Res. 2018, 28, 1532-1542. [CrossRef]

29. Wagner, J.R.; Busche, S.; Ge, B.; Kwan, T.; Pastinen, T.; Blanchette, M. The relationship between DNA methylation, genetic and expression inter-individual variation in untransformed human fibroblasts. Genome Biol. 2014, 15, R37. [CrossRef]

30. Lea, A.J.; Vockley, C.M.; Johnston, R.A.; Del Carpio, C.A.; Barreiro, L.B.; Reddy, T.E.; Tung, J. Genome-wide quantification of the effects of DNA methylation on human gene regulation. eLife 2018, 7, e37513. [CrossRef]

31. Eichten, S.R.; Briskine, R.; Song, J.; Li, Q.; Swanson-Wagner, R.; Hermanson, P.J.; Waters, A.J.; Starr, E.; West, P.T.; Tiffin, P.; et al. Epigenetic and genetic influences on dna methylation variation in maize populations. Plant Cell 2013, 25, 2783-2797. [CrossRef] [PubMed]

32. Wu, H.; Coskun, V.; Tao, J.; Xie, W.; Ge, W.; Yoshikawa, K.; Li, E.; Zhang, Y.; Sun, Y.E. Dnmt3a-dependent nonpromoter DNA methylation facilitates transcription of neurogenic genes. Science (N. Y.) 2010, 329, 444-448. [CrossRef] [PubMed]

33. Harris, C.J.; Scheibe, M.; Wongpalee, S.P.; Liu, W.; Cornett, E.M.; Vaughan, R.M.; Li, X.; Chen, W.; Xue, Y.; Zhong, Z.; et al. A DNA methylation reader complex that enhances gene transcription. Science (N. Y.) 2018, 362, 1182-1186. [CrossRef] [PubMed]

34. Maleszka, J.; Barron, A.B.; Helliwell, P.G.; Maleszka, R. Effect of age, behaviour and social environment on honey bee brain plasticity. J. Comp. Physiol. 2009, 195, 733-740. [CrossRef] [PubMed]

35. Evans, J.D.; Schwarz, R.S.; Chen, Y.P.; Budge, G.; Cornman, R.S.; De la Rua, P.; de Miranda, J.R.; Foret, S.; Foster, L.; Gauthier, L.; et al. Standard methods for molecular research in Apis mellifera. J. Apic. Res. 2013, 52, 1-53. [CrossRef]

36. Lin, P.; Foret, S.; Wilson, S.R.; Burden, C.J. Estimation of the methylation pattern distribution from deep sequencing data. BMC Bioinform. 2015, 16, 145. [CrossRef]

37. Becker, N.; Kucharski, R.; Rossler, W.; Maleszka, R. Age-dependent transcriptional and epigenomic responses to light exposure in the honey bee brain. FEBS Open Bio 2016, 6, 622-639. [CrossRef]

(C) 2020 by the authors. Licensee MDPI, Basel, Switzerland. This article is an open access article distributed under the terms and conditions of the Creative Commons Attribution (CC BY) license (http://creativecommons.org/licenses/by/4.0/). 